\title{
EL USO POLÍTICO DE LAS CONMEMORACIONES: \\ EL MITO DE AZAÑA Y EL SACRIFICIO DE SUÁREZ
}

\author{
The political use of commemorations: \\ The myth of Azaña and the Suarez's sacrifice
}

\author{
JUAN MARÍA SÁNCHEZ-PRIETO \\ Universidad Pública de Navarra \\ juanma.sanchez@unavarra.es
}

\author{
Cómo citar/Citation \\ Sánchez-Prieto, J. M. ${ }^{\underline{9}}$ (2017). \\ El uso político de las conmemoraciones: \\ el mito de Azaña y el sacrificio de Suárez. \\ Historia y Política, 38, 315-345 \\ doi: https://doi.org/10.18042/hp.38.11
}

(Recepción: 31/03/2016. Evaluación: 29/06/2016. Aceptación: 08/08/2016. Publicación: 10/11/2017)

\section{Resumen}

El objeto de este trabajo es la consideración de Azaña como lugar de memoria al filo de las conmemoraciones de su nacimiento y muerte, en 1980 y 1990, que llegaron a convertir a Azańa — denostado por el franquismo- casi en objeto de culto nacional. Asimismo se pretende abordar el uso político de Azańa en ese contexto, particularmente ligado a la recreación y disputa del centro político durante la década de hegemonía socialista. Un uso que no se limita, como ha señalado hasta ahora la historiografía, a la instrumentalización partidista de su figura por parte del nuevo Partido Popular de Aznar en los primeros años de la década de 1990. Con anterioridad ya lo hicieron Tierno Galván y Adolfo Suárez. En el transcurso de la década conmemorativa, Suárez usó de manera particular la comparación con Azaña y, creado el Centro Democrático y Social (CDS), buscó hacer del nuevo partido la enseña del neoazañismo, un nuevo Partido Socialista Popular (PSP) a su medida, contando para ello con la ayuda de Morodo. La reivindicación de Azaña por parte de Aznar no sería entonces sino la expresión de una decidida voluntad por hacerse con la herencia 
íntegra de Suárez, una vez consumado el sacrificio político de este, a modo de último ritual de la conmemoración.

\section{Palabras clave}

Conmemoraciones; usos políticos del pasado; Azaña; Adolfo Suárez; democracia; España.

\section{Abstract}

The goal of this work is to take into account the figure of Manuel Azaña as a lieu de la memoire laying upon the conmmemorations of his birth and death, in 1980 and 1990, events which turned Azaña — reviled during the Francoist dictatorship — into an almost revered national icon. I will analyze the political use of Azaña in this context, particularly linked to the political quarrels to hold the political centre during the decade of socialist hegemony. This political use is not limited, as historiography has noted until now, to the partisan instrumentalization of that figure made by the new Partido Popular of Aznar at the beginning of the 90s. Tierno Galván and the former president Suárez have tried as weel to use Azaña's memory. In the course of the conmmemorative decade, Suárez projected in a original way the comparison with Azaña and, once created the CDS, looked for to transform the new party in the banner of the so called neoazañismo, in other words, a new PSP made to mesure for him, being helped to fulfill that project by Morodo. The recognition of the figure of Azaña by Aznar is easy to understand along this path, trying to appropriate with decisiveness that political legacy from Suárez, once this was politically sacrified, as the latest stage of a series of iterative commemorative rituals.

\section{Keywords}

Commemorations; political uses of the past; Azaña; Adolfo Suárez; Spain; democracy. 


\section{SUMARIO}

I. INTRODUCCIÓN. II. LA RESURRECCIÓN DE AZAÑA: 1. El centenario del nacimiento. 2. El cincuentenario de la muerte. 3. La polémica. III. EL USO POLíTICO DE AZAÑA: 1. La ambivalencia de Tierno Galván. 2. La reinvención política de Suárez. 3. El alejamiento del rey. 4. La aventura neoazañista del CDS. 5. La disputa de Azaña y del centro tras el sacrificio de Suárez. IV. A MODO DE CONCLUSIÓN. Biblografía.

\section{INTRODUCCIÓN}

Las relaciones entre «historia», "política» y «sociedad» encuentran en la «memoria» un nexo y un campo de estudio que ha renovado la investigación en disciplinas afines durante las últimas décadas. Nuevos conceptos como la «historia pública», los «usos de la historia» o los «lugares de memoria» se han extendido rápidamente multiplicando debates y estudios de diversa índole ${ }^{1}$. La monumental obra de Pierre Nora ha marcado particularmente el camino, multiplicando el interés por las diversas formas de representación del pasado donde mitos, símbolos y tradiciones se funden con el propio conocimiento histórico. Las conmemoraciones ejercen un papel fundamental en ese sentido, no tanto para ayudar a entender mejor la historia como para recomponer la memoria ${ }^{2}$. Una necesidad ligada a las vicisitudes presentes del grupo, comunidad o nación, y a los intereses políticos inmediatos de los agentes, como ha profundizado Nora ${ }^{3}$.

El ansia conmemorativa manifiesta que una sociedad no puede vivir sin calendario ${ }^{4}$. A fuerza de celebraciones y conmemoraciones se excita la memoria y el reconocimiento a veces obsesivo de las raíces donde fundar el porvenir. La conmemoración opera una transferencia de sacralidad de lo religioso a lo profano. Históricamente ha sido un componente efectivo del culto que la nación se da a sí misma, y una pieza básica de la "política de la memoria»

1 Véanse las revistas The Public Historian (desde 1978) o Public Histoire (1983-2013), y las obras de Nora (1984-1993); Bodnar (1992); Ricoeur (2000); Hartog-Revel (2001); Revel-Levi (2002); Carreras-Forcadell (2003); Bussière-Moradiellos (2012), y González Calleja (2013), entre otras.

2 Olábarri (2013): 286-287.

3 Nora (2011).

4 Le Goff (1991): 184-226. 
alentada desde cualquier Gobierno o grupo con aspiración de poder o de sobrevivir culturalmente, oponiéndose al trabajo del olvido. Permite a cualquier colectividad reconstruir su relación con el tiempo y refuerza la conciencia de identidad ${ }^{5}$. La reactualización del pasado por el presente, a través de la recuperación/fabricación de la memoria, aun a costa de la historia, es inseparable de la propia aspiración de construir el futuro.

A partir de la crisis de la década de 1930 y la nueva experiencia de la guerra, se opera — sugiere Nora- una auténtica metamorfosis de la memoria. La idea de una memoria nacional unitaria sufre una fuerte erosión y la legitimación por la historia cede el paso a la legitimación por el futuro ${ }^{6}$. Es lo que sucede con la restauración de la democracia en España, después de la Guerra Civil y el franquismo. El «pacto del olvido» — la necesidad de olvidar un pasado traumático, que no se desconoce pero no cabe venerar- alentó de manera inmediata una visión pragmática del futuro. No se trataba tanto de obviar un "deber de memoria" con respecto a ese pasado reciente como de reconocer el «derecho al olvido» — en el juego imperante de generacionespara favorecer la necesaria reconciliación y el consenso político 7 .

De hecho, la especificidad española hizo que los años setenta, mucho más que en otros lugares, favoreciesen una creciente pluralización de la memoria, vinculada a la afirmación de grupos sociales y territorios, y a la misma aceleración de la historia, propiciando la recuperación de la memoria cívica y democrática confiscada, manipulada y destruida durante la dictadura bajo el mito de la «España eterna» ${ }^{8}$. Al ritmo del calendario, es el presente histórico quien crea sus propios instrumentos de conmemoración, quien elige las fechas y figuras que recordar, quien rehabilita o condena y modifica el significado de aquellas. La democratización de España urgía a armar una nueva memoria colectiva, mucho más incierta, rota la continuidad de la relación con el pasado, a la hora de saber a quién y a qué debemos ser lo que somos ${ }^{9}$. El uso del pasado se adivinaba mucho más caprichoso.

El objeto de este trabajo es la consideración de Manuel Azaña como lugar de memoria al filo de las conmemoraciones de su nacimiento y muerte, en 1980 y 1990; dos fechas rememorativas, jalonadas por el cincuenta aniversario del inicio de la Guerra Civil (1986), que registraron una auténtica explosión de la memoria en plena Transición y consolidación democráticas, hasta

Véanse, entre otros, Gillis (1994) y Cottret-Henneton (2010).

Nora (2011): 300, 401, 411-412.

Véanse, entre otros, Aguilar (1996); Sevillano (2003), y Pasamar (2014).

Sánchez-Prieto (2005): 300 y ss.

$9 \quad$ Nora (1993): 985; Nora (2011): 302, 384, 413, con mención al caso español. 
convertir a Azaña — símbolo de la Segunda República denostado por el franquismo - casi en objeto de culto nacional. Asimismo se pretende abordar el uso político de Azaña en ese contexto, particularmente ligado a la recreación y disputa del centro político durante la década de hegemonía socialista. No fue, sin embargo, el Partido Socialista Obrero Español (PSOE) el principal artífice de la recuperación de Azańa. Marichal, que se refirió en 1994 a ese empeño conmemorativo, apunta un cierto desdén socialista en momentos señalados. Por otro lado, Reig ha enfatizado la instrumentalización oportunista de Azaña por parte del nuevo Partido Popular (PP) a principios de los ańos noventa, traicionando la memoria del personaje, aspecto que ha sido tratado de manera más matizada por Palau ${ }^{10}$.

La hipótesis que se plantea en este estudio, es que la disputa del centro político — como llave que asegura el poder, según la percepción inmediata—, estuvo ligada entonces a una disputa de Azaña, y que en esa pretensión de utilizar políticamente su memoria, posiblemente quien más destaque, junto a Tierno Galván, sea Adolfo Suárez, aspecto que no consideran Marichal, Reig ni Palau, y que no ha sido tampoco tratado en las biografías disponibles sobre él. 1980 y 1990 son años singulares en la vida política de Suárez, que van de la operación de acoso y derribo que sufrió dentro y fuera de Unión de Centro Democrático (UCD), a su segunda derrota política al frente del CDS. Es el momento azañista de Suárez, a cuya luz cabría entender mejor el carácter ideológico del Centro Democrático y Social (CDS) o el deterioro de sus relaciones con el rey Juan Carlos. La reivindicación de Azaña por parte de Aznar no sería entonces sino la expresión de una decidida voluntad por hacerse con la herencia íntegra de Suárez, una vez consumado el sacrificio de este, a modo de último ritual de la conmemoración. Con todo, por encima de intereses políticos encontrados, esta común apropiación de Azaña en los comienzos de la nueva andadura democrática supone quizá la mejor muestra en España de la voluntad de recomponer «una» memoria colectiva, por efímera que resultase.

\section{LA RESURRECCIÓN DE AZAÑA}

No fue Azaña un caso aislado en el proceso de recuperación de la memoria intelectual y política silenciada por la dictadura. Desde comienzos de la Transición, otras celebraciones como el cincuentenario de la generación del 27 (1977), seguido — como ha punteado Mainer ${ }^{11}$ — de los centenarios de Miró

$10 \quad$ Reig (1996): 342-346; Palau (2007): 63-64

11 Mainer (1991): 384-387 («Las 'recuperaciones' y otros fastos»). 
(1979), Pérez de Ayala (1980) y Juan Ramón Jiménez (1981), sirvieron de pórtico a los centenarios de Azańa (1980) y Ortega y Gasset (1983), de mayor resonancia por el calado y proyección de ambos en la historia española. De acuerdo con su perfil, la conmemoración de Ortega tuvo mayor resultado intelectual que alcance político, como evidenció la labor desarrollada por la Fundación Ortega y Gasset entonces inaugurada. El revival de Azaña adquiere, por el contrario, un mayor significado político favorecido además por el doblete festivo. Tampoco debe olvidarse el centenario de Marañón (1987).

La rehabilitación de Azaña reviste, en cualquier caso, mayor importancia atendiendo al hecho previo de su satanización. La imagen, utilizada por Raúl Morodo con ocasión del cincuentenario de la muerte ${ }^{12}$, es retomada por Reig para ilustrar el infierno masónico al que Azaña fue condenado por la propaganda franquista ${ }^{13}$, aunque no se detiene en el análisis de la bibliografía que construyó la leyenda negra de Azaña, ya en vida de este. Obras diferentes como el Azaña de González Ruiz (1932), las Profecías españolas de Giménez Caballero (1932), el Azaña y ellos de Casares (1938) o las Memorias intimas de Azaña debidas a Arrarás (1939), siguen despertando interés académico, según manifiestan trabajos novedosos como el de Pulido (2011) ${ }^{14}$.

El libro de Giménez Caballero, reeditado durante el tardofranquismo ${ }^{15}$, reviste particular curiosidad al tratarse de una obra cuyo primer impulso era encomiástico. En clave fascista, buscaba hacer de Azaña el hombre que se necesitaba para modernizar el país, y acabó fijando todos los elementos de la representación deforme de Azaña que fomentaron sus detractores ${ }^{16}$. Genio y demonio a la vez, el mito de Azaña surgía vigoroso. La expresión la incluye Araquistáin en el título de un artículo publicado en Leviatán antes de la Guerra Civil ${ }^{17}$, y se encuentra de nuevo en las memorias políticas de Gordón Ordás — ministro con

Morodo, R., «La diabolización de Azaña», El Pais, 29-10-1990.

13 Reig (1996): 324-329.

14 Véase también la reseña de Egido (1998: 33-39) sobre los «azañófobos», y la valoración de los mismos en Palau (2007): 56-59.

15 La reedición de 1975, con estudio preliminar de Béracaud, lleva prólogo nuevo del propio Giménez Caballero.

16 El mencionado estudio de Pulido analiza los diferentes recursos literarios de Giménez Caballero asociados a esa imagen deformada, y la influencia en ellos de conocimientos científicos de la época así como de técnicas de las vanguardias artísticas y literarias.

17 Araquistain, L. (1935), «El mito Azaña», Leviatán, 18, 1-6. Se pregunta por el «milagroso magnetismo» de su figura, capaz de atraer multitudes y de concitar odios. Si Azaña es un "mito demoniaco creado por las derechas», también "personifica hoy el buen demonio socrático de las izquierdas españolas, no sólo por perseguido, sino también por ser el republicano más representativo de la revolución democrática en España». 
Martínez Barrio y luego presidente del Gobierno de la República en el exilio-, aunque este al referirse al «mito fabuloso» de Azaña revierta el sentido utópico que le dio el intelectual socialista — la transformación democrática de España-, para reducir su gloria política a la dimensión del "gran fracasado»"

Genio y demonio, gloria y fracaso, la ambivalencia de la figura de Azaña superó inicialmente la estricta dialéctica del nosotros y ellos, inevitable en el marco de la Guerra Civil, para abrirse al juego del mito y la crítica, mucho más efectivo en términos de memoria y olvido. En cualquier caso, sepultado bajo el peso de la hipercrítica, las conmemoraciones de su nacimiento y muerte supusieron una auténtica resurrección de Azaña. Ya en los años finales del franquismo, la biografía de $A_{\text {guado }}{ }^{19}$ (1972), con aroma unamuniano y machadiano, o la novela — premio Planeta — de Rojas ${ }^{20}$ (1973), acusado de plagio por doña Dolores Rivas Cherif ${ }^{21}$, prepararon la reivindicación de la memoria de Azańa, que todavía se antojaba como «absurda», "caprichosa»y «sospechosa» ${ }^{22}$. En los años de la Transición, entre 1976 y 1979, se cifran unas ochenta publicaciones referidas a él ${ }^{23}$. La entrevista de los reyes con la viuda de Azaña durante su visita oficial a México en 1978, en vísperas del referéndum constitucional, compartiendo con ella el sentir de reconciliación de los españoles, tuvo un alto significado simbólico ${ }^{24}$. Pero el comienzo efectivo de su restauración histórica, como ha señalado Marichal ${ }^{25}$, fue 1980.

\section{EL CENTENARIO DEL NACIMIENTO}

La resurrección de Azaña resulta mucho más asombrosa e interesante por cuanto no surge de una conmemoración de Estado, según el viejo modelo,

18 «Acabó por formarse en torno a él un mito fabuloso, que yo procuré destruir sin fuerza suficiente para conseguirlo, porque veía en el mito Azańa un peligro tremendo para la vida normal de la República», incide Gordón Ordás (1962, II: 13 y ss.).

19 Aguado (1972).

20 Rojas (1973).

21 Los juicios de la viuda de Azaña, en Informaciones, 2-02-1974.

22 Argos, "A vuela pluma», $A B C, 17-11-1973$.

23 Alted (1996): 17.

24 Informaciones y $A B C, 21-11-1978$.

25 Marichal (1994): 30. En ese mismo trabajo, Marichal detalla la historia de su dedicación a Azaña, que tanto contribuyó desde la preparación de sus Obras Completas (1966-1968) a la restauración intelectual de su figura, muy consciente de la significación futurible de ese trabajo. 
sino de las profundidades de la sociedad civil, haciendo entrar en escena todos los géneros culturales (de las celebraciones al teatro o la televisión, y de los periódicos y revistas a la historiografía). Desde el Gobierno de UCD, impulsada por la Dirección General de Patrimonio, Archivos y Museos que llevaba el historiador Javier Tusell, se organizó (octubre-diciembre) una exposición sobre la Guerra Civil en el Palacio de Cristal del Retiro, donde fue elegido Azaña presidente de la República, «todo un símbolo para demostrar que ya no hay motivos en España para dejar en la oscuridad ningún aspecto de nuestra historia, y menos de la historia de la Guerra Civil», afirmaba Tusell en la inauguración. Los materiales de la muestra, cedidos por instituciones y coleccionistas privados, incluían armas y objetos de uso cotidiano, carteles, banderas, insignias, maquetas, documentos fotográficos y fílmicos, etc., relativos a los dos bandos. La exposición acababa con imágenes de las dos Españas —la del exilio y la que vence- proyectadas sobre un espejo ${ }^{26}$.

Propiamente dicha, la primera celebración institucional del centenario fue el homenaje tributado por el Ayuntamiento de Madrid (noviembre de 1980), a impulsos de Tierno Galván ${ }^{27}$. Fue precedido de una representación en el Teatro Bellas Artes de La velada en Benicarló, donde se revivió de manera impresionante el Azaña de 1937 — la intensidad de su dolor durante la tragedia española-, con buena respuesta de la audiencia ${ }^{28}$. Se había preparado durante meses queriendo ser fieles a la obra de Azaña — «oratorio civil» para José Luis Gómez, director y responsable de su adaptación junto a José A. Gabriel y Galán- y trasladando al escenario la «tremenda capacidad de emoción» que el texto provocaba ${ }^{29}$. No fue la única escenificación. En 1988, Gómez - con la colaboración de José María Marco, que seleccionó los pasajes- estrenó en el teatro María Guerrero el monólogo Azaña: una pasión española ${ }^{30}$, luego representado en varios países hispanoamericanos con gran éxito. Era seguramente el mejor homenaje a Azaña, apasionado del teatro.

En el Ateneo de Madrid, donde desde principios de año Acción Republicana Democrática Espańola había organizado algunos actos en memoria de Azaña, se presentó la reaparición de La Pluma ${ }^{31}$, la revista cultural fundada en 1920 por Azaña y Cipriano Rivas Cherif, que iniciaba ahora su segunda

26 El País, 22-10-1980. ABC, 22-10-1980. Catálogo de la exposición.

27 Se trató de un ciclo de conferencias pronunciadas por Marichal, Francisco Ayala y el propio alcalde Tierno.

28 Se mantuvo en cartel hasta mediados de 1981 (Azaña, 1981).

29 El País, 11-7-1980 y 6-11-1980.

30 Véase la crítica en Reseña, 187, 1988: 7-8.

31 El Pais, 23-1-1980 y 20-12-1980. 
época, aun entendiendo que se trataba de una revista irrepetible. Bajo la presidencia honorífica de Jorge Guillén (dado a conocer antaño en la revista), y coordinada por Julio Vélez, figuraba el sobrino de Azaña como editor ${ }^{32}$. En el mismo Ateneo - tan vinculado al intelectual y político republicano- se presentó igualmente el sentido libro de Josefina Carabias ${ }^{33}$, con intervenciones del líder del PSOE, Felipe González, y del editor de Diario 16 y Cambio 16, Juan Tomás de Salas, quien, a diferencia del primero, no dudó en realizar comparaciones entre el pasado y el presente ${ }^{34}$.

Los artículos de prensa se sucedieron a lo largo de 1980 y no faltaron las páginas especiales o los suplementos conmemorativos. El País fue el primero, con editorial y firmas como López Aranguren, Tunón de Lara o Francisco Nieva $^{35}$. Blanco y Negro y $A b c$, los últimos, aunque comprometidos en subrayar la «vigencia y recuperación» de Azaña ${ }^{36}$, y trazar su perfil como escritor ${ }^{37}$. Entre los libros académicos, destaca el volumen de homenaje, de alcance internacional, coordinado por Serrano y San Luciano (1991), que además de las colaboraciones de los especialistas ${ }^{38}$, incluía algunas fotografías y textos inéditos de Azaña. Fue presentado en el Teatro Bellas Artes (coincidiendo con las representaciones de La velada en Benicarló) y será reeditado, con pequeños cambios, en el cincuentenario de la muerte (id.). El número total de publicaciones dedicadas a Azańa (libros, capítulos y artículos de todo tipo) durante la década de los ochenta, al calor del centenario, se eleva a unos 350 , según los cálculos realizados ${ }^{39}$.

A impulsos de la conmemoración, desde la Dirección General que encabezaba Tusell, comenzó en 1980 la búsqueda de los papeles de Azaña ${ }^{40}:$ los cuadernos personales extraviados en 1936 y el archivo confiscado por la Gestapo en Francia en 1940. Este último apareció sorpresivamente en 1984, repartido entre

\footnotetext{
32 Necrológica de Manuel Martínez Azaña, El País, 19-12-2000.

33 Carabias (1980)

$34 \quad A B C, 4-12-1980$.

35 El País, 10-1-1980.

36 «Vigencia y recuperación de Manuel Azaña», Blanco y Negro, 12-11-1980, 49-51 (con colaboraciones de Tusell, Palacio Atard, Marichal y Justino Azcárate).

37 ABC-Sábado cultural, 29-11-1980.

38 Jorge Guillén, José Bergamín, Ayala, Giménez Caballero, Marichal, Manuel Aragón, Franco Meregalli, Gabriel Jackson, Paul Preston, Hugh Thomas, Santos Juliá, Setién Florensa, Bécaraud, Mainer, Tunón de Lara y Francisco Villacorta. Marichal (1994: 14) lo considera el mejor volumen colectivo sobre Azańa de las conmemoraciones.

39 Alted (1996), loc. cit.

40 El Pais, 30-10-1980.
} 
las dependencias de la Escuela Superior de Policía de Madrid y de la antigua Dirección General de Seguridad ${ }^{41}$. Los ministros Barrionuevo y Solana se disputaron el hallazgo, pero el Gobierno socialista acabó entregando el archivo a la viuda del presidente en lugar de depositarse en el Archivo Histórico Nacional ${ }^{42}$. Una decepción, no solo para los estudiosos, como también lo había sido antes que Azaña quedara fuera de los cambios del callejero de Madrid ${ }^{43}$. Aun con buena presencia en distintos medios y géneros de expresión cultural, todavía quedaba camino para la conversión de Azaña en lugar de memoria.

\section{EL CINCUENTENARIO DE LA MUERTE}

La conmemoración de la muerte tuvo un anticipo en el cincuenta aniversario del discurso más representativo del último Azańa — conocido por la invocación «paz, piedad, perdón»—, recordado solemnemente por $A B C^{44}$, y que enlazaba a su vez con el cincuentenario de la Guerra Civil. En 1990, el periódico monárquico sorprendía de nuevo con un suplemento esforzándose en recomponer una imagen plural del antiguo "enemigo», y promoviendo luego la calle pendiente en Madrid en memoria suya ${ }^{45}$. También destacó el tratamiento otorgado entonces por El Mundo, recién creado, o por revistas culturales como Insula ${ }^{46}$. El Palacio de Cristal del Retiro acogió esta vez una exposición muy representativa del personaje, preparada por J. M. Marco, comisario de la misma, bajo el patrocinio del Ministerio de Cultura dirigido por Jorge Semprún, que la inauguró junto al alcalde de la capital Rodríguez Sahagún ${ }^{47}$. El otro escenario fundamental de la conmemoración de 1990 fue

41 Un resumen descriptivo de los papeles hallados, en Egido (1998): 15-17.

42 Marichal (1994: 36) se refirió al hecho como «el secuestro de Manuel Azaña». Todavía en 1997, con ocasión de la aparición de los 'cuadernos robados' de Azaña, este asunto sería utilizado por la entonces ministra de Cultura Esperanza Aguirre para criticar a los socialistas ( $A B C, 20-2-1997)$.

43 El Pais, 25-1-1980.

44 Suplemento «Recuerdo de Manuel Azaña», $A B C, 8-5-1988$.

45 «Imagen plural de Manuel Azaña», ABC Literario, 3-11-1990, con colaboraciones, entre otros, de José Prat, Ricardo Gullón, Morodo, Marichal, Jiménez Losantos, Gustavo Villapalos, José María Aznar y Juliá (la portada del diario también estaba dedicada a Azaña). Jiménez Losantos, F., «Azaña sigue sin calle», $A B C, 13-1-1991$.

46 Insula, núm. 526, 1990.

47 Catálogo de la Exposición Azaña (noviembre 1990-enero 1991). Aun anotando la presencia del ministro del Gobierno socialista (no la del alcalde), Marichal reprocha que no acudiesen «otros cargos gubernamentales más altos» a rendir homenaje a la memoria 
Montauban, la ciudad donde descansan los restos mortales de Azańa y que acogió para la ocasión a un buen plantel intelectual en un congreso organizado por el CNRS francés, de amplia resonancia ${ }^{48}$.

Durante unos días se repuso en el Teatro María Guerrero la obra Azaña, la pasión española, estrenada dos años antes. Pero la mayor novedad, ampliándose los medios de difusión cultural y las audiencias, fue la televisión. Televisión Española (TVE) estrenó una serie documental —Manuel Azaña, un soñador sin ventura - dirigida por Fernández Cormenzana. Un antiguo locutor de Radio España Independiente, la Pirenaica en tiempos de la clandestinidad, Ramón Mendezona, interpretaba la voz de Azaña ${ }^{49}$. En Cataluña, por problemas de encaje con la programación cultural propia, se relegó su emisión a la madrugada, pero las protestas elevadas obligaron a TVE a reponer la serie $^{50}$. La vigésima edición del Festival de Cine de Alcalá de Henares incluyó dentro de sus programaciones una sección dedicada al cine español durante los años de la Segunda República donde se proyectaron también los cinco capítulos emitidos por TVE ${ }^{51}$. No faltaron programas especiales en otras cadenas, como el de Jiménez Losantos que emitió Antena $3^{52}$.

El catálogo de la exposición del Palacio de Cristal incluía un trabajo de Enrique Rivas (hijo de Cipriano) que recopilaba y analizaba la bibliografía vertida sobre Azaña entre 1920 y $1988^{53}$. La producción sobre Azaña —escribía«parece recibir un estímulo solo en las ocasiones conmemorativas o siguiendo los movimientos de las modas impredecibles y arbitrarias». A pesar del gran material disponible, faltaban a su juicio obras de auténtico valor historiográfico sobre aspectos clave de la actuación política de Azaña así como estudios analíticos, globales y metódicos de sus escritos fundamentales. La explosión de

del presidente Azaña (Marichal, 1994: 37). El cuñado y compañero político de Suárez, Rodríguez Sahagún, cuyo padre había militado en la Izquierda Republicana de Azańa, acababa de entrevistarse con Dolores Rivas en Méjico (El País, 28-8-1990).

Los trabajos reunidos para el evento, en Almaric-Aubert (1993). Sobre el simbolismo del homenaje en Francia, véase Palau (2007): 60-61. No fue el único coloquio académico. Raúl Morodo dirigió un curso de verano en El Escorial (UCM), con el título de Revisión de Azaña, y hubo otra iniciativa notable en Barcelona.

49 Los cinco documentales se emitieron entre el 10 de octubre y el 14 de noviembre.

50 El Pais, 14-11-1990.

51 El Pais, 25-11-1990.

52 Antena 3, 8-11-1990, 23:30 horas: Programa especial con motivo del 50 aniversario de la muerte de Azaña.

53 Rivas, E., «Hacia una bibliografía de Azaña. Obras sobre Manuel Azaña». En Azaña (1990), pp. 343-373. 
títulos de los años ochenta ya proporcionó monografías de corte académico ${ }^{54}$, aunque ciertamente los trabajos de mayor peso historiográfico, o más propiamente de investigación, que echaba de menos Rivas, se aproximan mucho más al polo conmemorativo de 1990, fuera ya del alcance de su reseña. Las obras de Marco y Juliás ${ }^{55}$, así como algunas tesis doctorales ${ }^{56}$, son representativas en ese sentido dentro de una nueva floración de títulos (cerca de doscientas publicaciones registradas en periódicos, revistas y colecciones en apenas dos meses, además de libros y reediciones ${ }^{57}$ ), y que con ritmos distintos no se ha detenido en las primeras décadas del siglo $\mathrm{XXI}^{58}$.

Con todo, en ningún momento el empeño conmemorativo del último presidente de la república española —en las fechas que nos ocupan — tuvo algo de reivindicación de aquel régimen, ni de crítica combativa como reacción como ha sucedido en fechas más recientes-, sino que supuso antes que nada una reflexión sobre la tolerancia liberal y el perfil laico y nacionalista español del personaje. Hasta que estalló la polémica, cuyos motivos conviene precisar.

\section{LA POLÉMICA}

El detonante principal fue la obra de Jiménez Losantos, La última salida de Manuel de Azaña, premio Espejo de España 1994. El autor contó entre quienes contribuyeron a la recuperación de Azaña en las horas tempranas de la Transición y de la primera conmemoración ${ }^{59}$. También figuró en 1990 entre los azañólogos de firma en los cuadernos culturales, al lado de Marichal o Juliá, sin que su posición fuera entonces discutida. El libro componía un cúmulo de imágenes antes que un argumento, pero el perfil del autor — periodista

Espín (1980); Marichal (1982); Marco (1988).

55 Marco (1990) (1991); Marco y Serrano (1990); Juliá (1990).

56 Véanse Peña González (1991): tesis doctoral original leída en 1981 en la UCM, y Ferrer Solá (1991): tesis presentada a finales de los ochenta en la UB.

57 Egido (1998: 17-19) refiere algunos libros y reediciones de los primeros ańos de 1990, a los que se pueden añadir (en la línea apuntada por Rivas): Hermosilla Alvarez (1991), Cañizal-Otero (1991) y Fernández-Cormenzana (1994).

58 Destaca en ese sentido la nueva edición a cargo de Santos Juliá de las Obras Completas de Azaña (2008).

59 Además de alguna aportación sobre aspectos literarios (Jiménez Losantos, 1978), sus antologías de los escritos de Azaña (1982-1983) contribuyeron a popularizar al político republicano. Estos trabajos no son mencionados por Marichal en su reseña de 1994 sobre la restauración de Azańa, tal vez inspirada por la propia polémica. 
particularmente crítico con el socialismo felipista - y la forma presuntuosa de defender su derecho a tratar de las cosas de Azaña ${ }^{60}$ hicieron que su retrato del personaje se viera enseguida envuelto en la polémica. Participaron en ella historiadores que habían destacado en la conmemoración, como Tusell y Juliá, críticos con Losantos, o Marco, que acudió a apoyarle.

Juliá, cuya biografía sobre Azaña es ignorada por Losantos, le censuró que plagiase párrafos enteros del Retrato de un desconocido de Cipriano Rivas Cherif ${ }^{61}$ e introdujo la cuestión del uso político del pasado. El empeño de Jiménez Losantos por rescatar al último Azaña, al «mejor» Azaña, como símbolo de la "tercera España» era toda una propuesta política, pero que reducía la historia a simple coartada, señalaba Juliá, y hasta aconsejaba un cambio de título: Manifiesto por una joven derecha liberal nacional española bajo la advocación de Manuel Azaña ${ }^{62}$. La presencia de Aznar en el acto de presentación del libro, junto al exministro Barrionuevo, en un contexto de declive del socialismo y ascenso del nuevo PP, no fue inocente. Marco, por su parte, celebraba que se hubiese rescatado a Azaña del republicanismo radical en que había quedado encerrado, y que se cifrara su herencia política en la primacía de un proyecto político nacional desde la afirmación del liberalismo y la democracia como ejes de actuación política ${ }^{63}$. La polémica alcanzó a publicaciones académicas. La atención desmedida que presta Reig a esta obra de Losantos, en un volumen colectivo por demás impecable, haciendo gala de un moralismo improcedente cuando argumenta en clave de «no tomarás a Azańa en vano", es todo un ejemplo ${ }^{64}$.

Con todo, y por criticada que fuera desde la izquierda cualquier resignificación de Azaña fuera de sus predios ideológicos, la utilización política de Azaña que hacía Losantos encerraba una particular contradicción. Su empeño por atribuir a Aznar la recuperación del mejor espíritu patriótico como elemento indisociable de su legado democrático ${ }^{65}$, acababa apartándose en lo fundamental del nuevo discurso que desde 1990 buscaba el PP. La pretensión de Losantos de erigirse en mentor de una derecha liberal traduce un claro desdén por el centro y

60 «Mi vida con Azaña», Jiménez Losantos (1994): 253-259.

61 Es una de las principales obras reeditadas en 1980, con introducción y notas de Enrique Rivas.

62 El Pais (suplemento Babelia), 16-4-1994. Acerca de la utilización hecha del libro de Rivas Cherif véase Jiménez Losantos, $A B C, 19-11-1994$ y Juliá, El País, 21-11-1994.

63 ABC Cultural, 8-4-1994. Marco, J. M., «El rescate del liberalismo», El Mundo, 18-9-1994.

64 Reig (1996): 334-346.

65 Jiménez Losantos, F., "Azaña y Aznar», $A B C$, 9-4-1994. 
la Transición, que según él, lejos de reivindicar la tercera España la enterró ${ }^{66}$. La visión que arroja de la UCD de Suárez, ya a principios de los años 1980, es la de un completo vacío ideológico que levantaba hasta en la izquierda la «demanda melancólica de una derecha democrática» ${ }^{67}$. Esa derecha liberal que Losantos no quiere identificar con el centro, es el centro que busca Aznar, que no quiere ser identificado con la derecha. A él apuntaba en la mirada que dirigió a Azaña durante la conmemoración de 1990, lamentando con Madariaga que el centro político no llegara a cuajar en la España de los años treinta ${ }^{68}$.

La novedad y atrevimiento de Aznar al frente de la derecha consistió en poner bajo el patronazgo simbólico de Azaña el empeño de reconstrucción del centro, y a la postre de la UCD, que vino a suponer la refundación del PP. Pero la instrumentalización política de Azaña no puede considerarse como la consecuencia retardada de una larga conmemoración, ni debe circunscribirse a Aznar y la polémica aludida. Ni siquiera fue realmente novedosa esa invocación a Azaña con fines políticos. El uso político de Azaña acompaña a toda la década conmemorativa, aunque no quepa vincularlo a los actos organizados o a las publicaciones programadas con motivo de los aniversarios, sino al uso que los políticos hicieron del personaje en la nueva atmósfera creada, particularmente ligado a la disputa del centro desde que comenzara a sentirse la crisis de UCD, y aun antes. Conviene detenerse en los principales jalones de este proceso, en el que la historiografía no se ha detenido hasta ahora, no solo para valorar con mayor perspectiva la refiguración del mito de Azaña durante la Transición y consolidación democráticas, sino para entender mejor el juego articulado de determinadas estrategias políticas y la suerte de algunos liderazgos.

\section{EL USO POLÍTICO DE AZAÑA}

La conmemoración de Azaña invitó a la comparación y a mirarse en su espejo. Desde El País, abriendo el homenaje, se le destacó como una de las «escasas figuras de la vida pública española que sobresalieron de la mediocridad, el conformismo y la vulgaridad, que tan abrumadoramente conformaron nuestro pasado y amenazan todavía con aplastar nuestro presente» ${ }^{69}$. Marichal

66 Jiménez Losantos (1994): 101-102.

67 «El momento conservador (Reflexiones sobre ideología y política en España tras el golpe de estado del 23-F)», originariamente en Diwan $(12,1981)$ y recogido en Jiménez Losantos (1995): 393-409 (véanse pp. 400-402).

68 Aznar, J. M., «Su figura, hoy», ABC Literario, 3-11-1990.

69 El País, 10-1-1980, editorial. 
invitó a la lectura sosegada de sus libros, en un clima de recogimiento colectivo, intentando evitar usos partidistas ${ }^{70}$, por más que el uso político en cualquiera de sus formas acabe siendo un efecto ineluctable de toda conmemoración. Sin que faltaran referencias al rey como nuevo ejemplo de la honestidad política que representó Azaña ${ }^{71}$, fueron Tierno y Suárez las figuras que más atrajeron la comparación o, quizá mejor, que más buscaron en algún momento la identificación con Azańa — mucho antes que Felipe González o luego Aznar-, en el transcurso del período referido. Ya a fines de 1980, figuras críticas dentro del socialismo como Gómez Llorente, temían que la «operación rescate» y la «apresurada digestión» de Manuel Azańa no respondiesen más que a «una maniobra de la derecha orientada a acallar malas concienciass ${ }^{72}$.

\section{LA AMBIVALENCIA DE TIERNO GALVÁN}

La trayectoria intelectual y política de Tierno Galván durante la dictadura estuvo caracterizada, según ha insistido Raúl Morodo, por la distancia no agresiva y estudiada propia del «fingidor forzado», pero que sin concesiones irá desarrollando una labor disolvente de la «cultura de hibernación» característica del franquismo oficial ${ }^{73}$. De personalidad compleja, nunca fue un marxista ortodoxo. Su concepto pragmático de la política le permitió aglutinar alrededor suyo un grupo diverso donde coexistían desde progresistas ilustrados hasta socialistas radicales de izquierda, convirtiendo la misma ambigüedad en un arma política eficaz en la lucha resistente por la democracia. Su presencia en la Junta Democrática de 1974 fue ya considerada por unos como una proyección subjetiva de Azaña, y por otros como una reactualización de Besteiro o Negrín ${ }^{74}$. Y aunque no pasó de alcalde, durante los dos lustros de democracia que contribuyó a llenar, el Viejo Profesor ejerció de alguna manera como pacificador krausista y presidente de una non nata III República española, como sugieren sus discípulos ${ }^{75}$. En Cabos sueltos, no deja de referir sus encuentros, siendo joven,

\footnotetext{
Marichal, J., «Azaña en su centenario», El País, 11-1-1980.

Balado, R., «Honestidad política», El País, 25-1-1980.

El País, 20-12-1980.

Morodo (1987): 160, 184.

Morodo, R., «Veinticinco años de lucha por la democracia», El País, 25-4-1978. José María Pemán, en plena Transición, consideraba un "pecado de desdén» el parangón entre Azaña y Tierno $(A B C, 11-5-1977)$.

75 Morodo, R., «Tierno Galván y la memoria histórica», El País, 19-1-1996.
} 
con Azaña y la impresión producida ${ }^{76}$. Esta secreta ambición de quien aceptara tempranamente la monarquía democrática como salida a la dictadura, será utilizada en su contra como un elemento del mito Tierno fabricado por él mismo ${ }^{77}$. Marichal, celebrando su iniciativa como alcalde en los actos conmemorativos de 1980, lo define como «azañista a su modo», aunque no insista en ello $^{78}$.

Fuera de la personalidad de Tierno, el Partido Socialista Popular (PSP) aspiró a ser un partido neoazañista, empeño que hay que reconocer posiblemente más a Morodo — cofundador y secretario general del mismo hasta 1978 - que al ilustre profesor. Veteranos observadores de la política supieron atribuir a Morodo el propósito de hacer del PSP un partido bisagra de centroizquierda (entre la UCD y el PSOE) ${ }^{79}$, y el propio interesado lo declaró abiertamente después de su autoexclusión del PSOE. Su proyecto político progresista y neoazañista chocaba frontalmente con los partidarios de articular un socialismo autogestionario a la izquierda del PSOE, a quienes descolocó igualmente la fusión de 1978 con el socialismo renovado de Felipe Gonzalez $^{80}$. Bien es verdad, y se le ha reprochado a Morodo, que en su momento faltó rotundidad en la explicación pública de esa orientación ${ }^{81}$, solo hecha explícita a posteriori, al calor del centenario de Azaña. Durante la Transición, la importancia sociológica del centroizquierda no se le escapará a Adolfo Suárez, que sabrá orientarse hacia ahí por razones más estratégicas que ideológicas, y con mayor decisión tras la desaparición del PSP. De hecho, el partido de Tierno había sido considerado por Suárez, ante las primeras elecciones de 1977, como un temido adversario para sus aspiraciones ${ }^{82}$.

76 Tierno Galván (1982): 37-41, 89.

77 Véase Alonso de los Ríos (1997): 13, 70-72, y el comentario de Morodo (2001: 130, 419) a esa obra.

78 Marichal (1994): 26. En la semblanza intelectual y política de Tierno que realiza poco después, subraya su pragmatismo, pero no hace referencia alguna a su querencia azañista (Marichal, 1995: 321-326).

79 Romero, E., $A B C, 13-6-1981$, calificando ese partido de neoazañista.

80 Morodo (1982): 169-199; García Santesmases (1993): 354-355.

81 Así lo hizo considerar A. De Blas Guerrero (1983), Revista de Estudios Politicos, 33, 260-261. En sus memorias, Morodo explica la división de funciones dentro del PSP y sus diferencias con Tierno, más visibles en lo ideológico, donde este "se imponía siempre, aceptando, a veces, ciertos frenos que yo le hacía». "Si tuviese que identificarme con algunos de los personajes de nuestra historia pasada lo haría con Azaña, Prieto y Araquistain", afirma también (Morodo, 2001: 450-451).

82 En el entorno inmediato de Suárez, personas como Carmen Díez de Rivera, su directora de gabinete, simpatizaron con el PSP, lo que llegó a producir tensiones entre ambos (Romero, 2002: 119-120, 143, 161, 163, 166-168, 183). 


\section{LA REINVENCIÓN POLÍTICA DE SUÁREZ}

De aquellas elecciones, surgió un segundo Suárez, legitimado democráticamente y con voluntad de permanecer en la política. Para ello necesitaba construir un verdadero partido y dotarle de coherencia ideológica ${ }^{83}$. La dimisión de Osorio en 1978 — su hombre de confianza en la primera etapa- contenía asombro, incomprensión y rechazo a la estrategia de Suárez de extenderse por su izquierda ${ }^{84}$. En el diseño de UCD que hizo Suárez, desplazar el centro de gravedad hacia la izquierda próxima, asegurar un polo progresista o socialdemócrata, era imprescindible no solo para aspirar a una mayoría de gobierno, sino también para contrarrestar las aspiraciones democristianas del polo de centroderecha. El centro debía constar de dos centros ${ }^{85}$. En este contexto, no faltaron referencias comparativas a Azańa, aun antes de 1980, favorecidas por Tarradellas, que elogió el coraje de Suárez con Cataluña ${ }^{86}$, haciendo valer la imagen de este como el hombre que «trajo y engatusó a la España desterrada o marginada ${ }^{87}$. De manera significativa, Jiménez Blanco, negando que existiera una crisis de identidad en UCD, aproximó el centro con pretensiones de centroizquierda de Suárez a Azaña, al buscar precedentes de crisis dentro de los partidos en la Segunda República ${ }^{88}$. No son, en cualquier caso, comparaciones que partan del propio Suárez, aunque tuviera ascendencia familiar republicana y revelara en su infancia la ambición de llegar a ser presidente de la República ${ }^{89}$.

Esa misma estrategia de ocupar el centroizquierda la mantuvo Felipe González, que después de absorber el grupo de Tierno y escenificar la renuncia del PSOE al marxismo (1979), se aproximó a los socialdemócratas de

83 La constitución de un comité ideológico dentro de UCD para ese fin fue ridiculizada por Cándido, «El bastón de Chateaubriand», Hoja del lunes, 3-10-1977.

84 Osorio (1980): 332.

85 Chamorro (1981): 154, 170.

86 «Lo que ha hecho Suárez no lo hizo Azaña», expresó Tarradellas tras la negociación del primer traspaso de competencias. «Ahora todo está en que lo ocurrido a Azaña, no le ocurra a Suárez, y que lo ocurrido a Companys no le ocurra a Tarradellas. Hay una fundada esperanza», escribía Cándido en $A B C, 18-4-1978$.

87 Romero, E., El País, 3-6-1978.

88 Jiménez Blanco, J., "Crisis de identidad en los partidos políticos», $A B C, 14-12-1978$. El paralelismo entre las dos figuras en las fechas del debate constitucional se encuentra también en comentaristas políticos de influencia como Capmany, evocando una visita de Azaña en 1931 a Cebreros, la villa donde nacería poco después Suárez $(A B C$, 19-10-78).

89 Fuentes (2011): 25-30, 532, 543. 
UCD de Fernández Ordóñez, quien en La España necesaria (1980), denunciando la derechización de UCD, no dejó de reivindicar a Azaña ${ }^{90}$. En pleno acoso interno y externo a Suárez, tras las mociones de censura y confianza en las Cortes, cuando se especula con un gobierno de coalición UCD-PSOE en la antesala del 23F, la excepcionalidad de la situación llegó a compararse con Azańa y la Ley de Defensa de la República ${ }^{91}$. Todo esto precede a la identificación pública de Suárez con Azaña, realizada durante la mencionada presentación del libro de Carabias en el Ateneo de Madrid, en el marco del centenario. Abstrayendo las diferencias entre ambos personajes, «se puede ver un paralelismo entre la personalización de la República en Azaña y la de la democracia en Suárez», afirmó Juan Tomás de Salas en presencia de Felipe González, que le había precedido en el uso de la palabra. El mensaje no era excluyente: «No queremos otro Azaña, porque queremos cien Azañas», sentenció el editor del Grupo 1692. Tal identificación, si no pasó desapercibida para González ${ }^{93}$, hizo seguramente también efecto en Suárez, y escandalizó a quienes ya habían hecho de su figura el estereotipo de la pura ambición de poder $^{94}$. El uso y los términos de la comparación se reactivaron con su dimisión, el problema de las autonomías o el fallido golpe de Estado, con valoraciones diversas ${ }^{95}$.

La disputa de Azaña, al calor de la conmemoración, parecía servida. Finalmente, la creación del Partido de Acción Democrática (PAD) por

90 Fernández Ordóńez (1980): 14, 17, 25-27. ABC, 21-3-1980. El propio González, cuyo padre era admirador de Azaña, comenzó a invocarle públicamente tras el congreso socialista de 1979, con mayor eco en la moción de censura presentada contra Suárez (Blanco y Negro, 19-12-1979; ABC, 29-5-1980; Diario 16, 30-5-1980).

91 El Pais, 9-11-1980.

92 El País, 4-12-1980. Esta manifestación de Salas se hacía poco después de la refundación del partido de Azaña, Izquierda Republicana, y de que en su manifiesto se hiciera una dura crítica de la Transición y del propio Suárez (El País, 1-10-1980). Manuel Iglesias, exfiscal general de la República y en la fecha presidente de la Comisión Constitucional del Senado, insistió en el paralelismo a propósito de la contestación que ambos políticos sufrieron (El País, 10-12-1980).

93 Pocos días después, González, reiterando su diagnóstico de grave enfermedad de la democracia española, abogaba por la necesidad de una ley de defensa de la democracia, emulando desde la oposición al Azaña de 1931 en el poder $(A B C, 19-12-1980)$. Morán (1979) y (1991): 172.

95 Véase, por ejemplo, C. Seco Serrano, «La empresa política de Adolfo Suárez: perspectiva histórica", $A B C, 5-2-1981$; Cándido, $A B C, 19-5-1981$ y E. Romero, $A B C, 21-5-$ 1981, a propósito de los nacionalismos y las autonomías; y E. Romero, $A B C$, 2-7-1981, en torno a la Sanjurjada de 1932 y el 23-F. 
Fernández Ordóńez, integrándose en el PSOE antes de las elecciones de 1982, supuso la culminación socialista a costa de Suárez de la misma estrategia que este había concebido para UCD. A mitad de 1982, las familias de UCD se habían convertido en "tribus que no se soportan y se canibalizan o se dispersan», en palabras de Calvo Sotelo. La posibilidad de un triunvirato Suárez-Lavilla-Calvo Sotelo, como última tabla de salvación, apenas decía algo a Suárez si no era para hacer «un partido nuevo que solo utilizara del anterior las siglas» ${ }^{96}$. Tal sería, a la postre, el desafío del CDS fundado por Suárez, que acabará proclamando de forma explícita el neoazañismo como bandera ideológica, aunque en vísperas del histórico triunfo del PSOE de 1982 quien se inspiraba y recordaba los mítines en campo abierto de Azaña era Felipe González ${ }^{97}$.

\section{EL ALEJAMIENTO DEL REY}

Algunos testimonios y semblanzas biográficas han insistido en la distancia creciente entre Suárez y el rey, una vez culminada la Reforma, aunque no sea fácil establecer con certeza los motivos. Podría inferirse que el empeño de Suárez por reinventarse políticamente, y los tintes que impregnaron su nuevo proyecto tras el $23 \mathrm{~F}$ y el colapso de UCD, quebraron la primera confianza. Según Díez de Rivera, su primera directora de gabinete y persona cercana igualmente al rey Juan Carlos, Suárez infringió el acuerdo inicial establecido entre ellos de no crear ningún partido y abandonar la Presidencia cuando estuviere instaurada la democracia, al querer reivindicarse a sí mismo más allá de la condición de instrumento del rey ${ }^{98}$. En 1977, con la legitimidad de las urnas,

96 Calvo Sotelo (1990): 82-85, 90. Calvo Sotelo no perdonó a Suárez su marcha de UCD, reprochándole el haber dejado el espacio político de centro imposible para él y para los demás.

97 P. Urbano, $A B C, 23-10-1982$; A. Anaut, Diario 16, 26-10-1982. Un editorial del diario de Tomás de Salas inmediato a la victoria socialista valoraba «la progresiva imitación, por parte de Felipe González, del estilo ético nacionalista de la oratoria de Manuel Azaña, particularmente en sus últimas intervenciones por TVE y en directo» (Diario 16, 30-10-1982).

98 Romero (2002): 154, 175, 198. Esa decisión de presentarse a las elecciones de 1977 habría contrariado también al rey, según algunas fuentes diplomáticas cuyo valor no es concluyente (Saiz, 2012: 321-322, 333-334). En todo caso, está asentada la opinión de que ese no era el plan inicial del monarca ni de Torcuato Fernández-Miranda (Fuentes, 2011: 201-202). 
Suárez aventajó al rey, que todavía no estaba legitimado por la Constitución. Esa disparidad de situaciones varió la relación política entre ambos y provocó ya algunos desacuerdos sobre el proceso constituyente, las autonomías, la política exterior o la cuestión militar. Desde 1979, constitucionalmente sometido el rey y reforzado el presidente, el modo de ejercer el poder sería aún más diferente. No hubo un hecho determinante para el desencuentro, pero se produjo, paralelamente a la persecución que el presidente sufrió durante 1980, hasta el punto de que don Juan Carlos llegó a compartir el temor de que su propia suerte pudiera quedar unida a la de Suárez, ha confirmado Abel Hernández ${ }^{99}$.

A finales de ese año, el mismo rey se mostró crítico con el desplazamiento hacia la izquierda que pretendía Suárez desde la $\mathrm{UCD}^{100}$. En un clima de frialdad y de desprestigio personal, Suárez presentó su dimisión, decisión que replanteó al rey inmediatamente después del $23 \mathrm{~F}$, donde se cargó de realidad la imagen de Suárez personificando la democracia, aunque nunca buscó utilizar esa circunstancia en su beneficio. El monarca accedió a otorgarle un título nobiliario a condición de que se retirara de la política. Creyera o no que lo haría, el rey dejó de llamarle, cortando radicalmente la relación, cuando Suárez creó el $\mathrm{CDS}^{101}$. Suárez no negó la distancia abierta, aunque evitó desde el principio cualquier manifestación que pudiera enturbiar «un mensaje claro sobre el rey y la monarquía constitucional ${ }^{102}$. De manera simultánea al alejamiento de Suárez, se producía el acercamiento entre el rey y el PSOE, en cuyas filas ya en la Transición y luego en el primer Gobierno socialista, se empleó la expresión de «república coronada» para referirse a la monarquía democrática ${ }^{103}$. Con independencia de la opinión que mereciera al rey el neoazañismo con que Suárez buscaría afianzar al CDS —en plena década conmemorativa del presidente republicano-, el hecho es que el reencuentro entre los dos no se produjo hasta que la desgracia personal comenzó a cebarse con el expresidente de la Transición, poco después de haber abandonado definitivamente la vida política ${ }^{104}$.

99 Hernández (2009): 106, 113-114, 126-131, 140-144, 151-152. Campo Vidal (2012): 110-111, 142. El desencuentro con el rey no puede desligarse de los que tuvo Suárez con dos hombres de confianza del monarca, Torcuato Fernández-Miranda y el general Armada.

100 Fuentes (2011): 354.

101 Hernández (2009): 183-188.

102 Así lo confiaba a Carmen Laviña (2010: 108) en una larga conversación durante la campaña electoral de 1982: «En el fondo, queda lo que compartimos juntos, que fue mucho».

103 Fuentes (2016): 273-275, 296, 306, 326, 333-336.

104 Hernández (2009): 199 y ss. 


\section{LA AVENTURA NEOAZAÑISTA DEL CDS}

El carácter luchador de Suárez se puso de manifiesto desde los comienzos del CDS, dispuesto a hacer crecer el partido desde las raíces a base de «esperanza, ilusión y frescura ${ }^{105}$. Suárez no pensaba de inmediato en las elecciones de 1982, sino en las siguientes, pero siempre tuvo claras las señas de identidad del partido. «El CDS ha nacido con una vocación de partido progresista y reformista, pero nuestro progresismo reside en la necesidad de que cada reforma, una vez terminada, siga teniendo capacidad transformadora de la realidad social, para que se convierta, a su vez, en instrumento o en motor de nuevas reformas", expresaba en 1982 y repetiría en adelante ${ }^{106}$. Si la idea de reforma había sido central en la Transición, ahora adquiría significado permanente. Estos conceptos clave se encuentran en la reivindicación de Azaña que hizo Suárez en la Revista de Occidente en 1985. El CDS recogía la "larga tradición» española de centro progresista y reformista que, aunque en distintas épocas no se le llamara así, arrancaba del regeneracionismo y llegaba al partido de Azańa para, soterrado durante el franquismo, reaflorar en 1976, explicaba ${ }^{107}$.

En esa apelación directa a Azaña por parte de Suárez se percibe la influencia de Raúl Morodo. De hecho, ese mismo argumento puede leerse en un artículo suyo con motivo del III Congreso del CDS ${ }^{108}$. Aunque se había especulado con la incorporación de Morodo al nuevo partido de Suárez el mismo día de su presentación ${ }^{109}$, fue tras el fallecimiento de Tierno Galván en 1985 cuando dio el paso, atraído no solo por su amistad con Suárez ${ }^{110}$, sino quizá también por la idea de hacer valer dentro del CDS el viejo proyecto del PSP que había acariciado y no logró abrirse paso bajo la jefatura de Tierno. Al fichar por el CDS, el histórico dirigente del PSP subrayó que el partido de Suárez

105 Laviña (2010): 70, 75.

106 Ibid: 134; Quevedo (2007): 278-279.

107 Entrevista de Ch.T. Powell con Adolfo Suárez, Revista de Occidente, 54, 1985: 143-151.

108 Morodo, R., «Novedad y continuidad histórica», El Pais, 29-3-1990.

109 Jáuregui, F., El País, 1-8-1982.

110 Morodo fue vecino de Suárez antes de que este residiese en Moncloa, donde continuaron celebrándose algunas cenas de matrimonios. En el curso de la Transición, como dirigente del PSP, estuvo en numerosos encuentros con Suárez. Sus pronunciamientos públicos acerca de las iniciativas o discursos de Suárez siempre fueron equilibrados y positivos, cuando no elogiosos. Suárez valoraba también sus juicios como catedrático de Derecho Político. Morodo se manifestó a favor de la elegibilidad de Suárez en 1977. 
representaba el centroizquierda, cuya tarea era limitar el excesivo poder del PSOE y consolidar la democracia ${ }^{111}$. A Suárez la aproximación de figuras como Morodo o Tamames le confería una especie de legitimación intelectual, a sumar a la anteriormente conseguida legitimidad democrática, al tiempo que reforzaba el significado simbólico del centro como reconciliación cultural, una imagen que había cultivado Morodo como embajador de la UNESCO $(1983-1984)^{112}$.

El hecho es que a partir del ingreso de Morodo, se aprecia una escalada en el neoazañismo del CDS, del II (1986) al III Congreso (1990) del partido, inseparable del empeño de Suárez por la reconquista del centro ${ }^{113}$. Tras el éxito de las elecciones generales de 1986, la apuesta por esa definición, hecha pública en el II Congreso, llamó la atención de Jiménez Losantos (futuro protagonista de la polémica que siguió al cincuentenario), quien exigía mayores precisiones sobre el pretendido azañismo de Suárez ${ }^{114}$. La respuesta de Morodo, subrayando la actualidad de Azaña para hablar no tanto de azañismo como de neoazañismo, incidió en ideas como la vigilancia y profundización de las libertades, la redefinición de las funciones del Estado o el asentamiento de la sociedad civil como garantía del desarrollo cultural, social y económico, en un clima de constante lucha por la distensión internacional, la solidaridad y la paz mundial. «El neo-azañismo hoy, en España, como yo lo veo, es necesariamente un liberalismo radical, una socialdemocracia y una actitud progresista en las relaciones internacionales», concluía ${ }^{115}$.

Son las ideas que pueden encontrarse en los principales discursos de Suárez de la época ${ }^{116}$, unidas a su inteligencia del centro progresista, aunque algunos dirigentes de su partido, como Boada en Valencia, admitan que «la ideología del CDS es algo difícil de explicar» ${ }^{117}$. El ingreso del partido en la Internacional Liberal (1988) pretendió clarificar y facilitar las cosas, por más que conllevara alguna baja como la de Díez de Rivera, que se había reencontrado con Suárez en

111 Entrevista a Raúl Morodo, Tiempo, 6-5-1985.

112 Morodo, R., «La Unesco, una nueva frontera para la paz», El País, 18-6-1984.

113 El uso político de Azańa sigue a los intereses intelectuales, reavivados al filo de la conmemoración. Morodo había dirigido la tesis doctoral de Peña González, antes citada, sobre los ideales políticos de Azaña.

114 Jiménez Losantos, F., "Azaña y Suárez», Diario 16, 17-9-1986.

115 Morodo, R., «Azañismo y neoazañismo», Diario 16, 19-9-1986.

116 Particularmente los discursos de Suárez en Pisa (1988), París (1989) y El Escorial (1989). Fragmentos significativos en Hernández (1996): 308-311, 318-319, 327-335. Véase también Quevedo (2007): 157, 253, 270-271.

117 Las Provincias, 28-8-1988. 
el CDS y le volverá a abandonar para ingresar en el $\mathrm{PSOE}^{118}$, sin acabar de entender que el liberalismo que abrazaba ahora Suárez era el liberalismo social de Azaña, fronterizo con el socialismo liberal de muchos ex del PSP no marxistas como ella. La crisis de identidad dentro del CDS se desata coincidiendo con el proceso de refundación del PP y el temor del PSOE a la pérdida de la mayoría absoluta. La necesidad de una tercera fuerza que evitara el bipartidismo, la bondad de un partido mediador que supiera acercar posturas de unos y otros, defendidas por Suárez ${ }^{119}$, quedaron en entredicho con los pactos CDS-PP establecidos antes de las elecciones europeas de 1989. La imagen de derechización que antaño lanzara Suárez contra la UCD (y que tanto dolió a Calvo Sotelo ${ }^{120}$ ) se volvía ahora contra él y el CDS.

Los retrocesos electorales de 1989 revelaron que ese paso, en respuesta al acoso del PSOE, había sido en falso, y muy bien explotado por los socialistas, como también a la postre por el PP. Ante la contestación interna y el recuerdo de la descomposición de UCD ${ }^{121}$, la ponencia política del III Congreso del CDS reconocerá que fue un error pactar con el PP y planteará un cambio estratégico dentro de una continuidad ideológica. Morodo lo traslada a la opinión. Los ejes ideológicos neoazañistas se mantienen («la defensa radical de las libertades públicas, la adhesión al Estado social-liberal y democrático de derecho y la concepción progresista de la paz y de la distensión internacionales»), o se intensifican, al definirse el CDS como "partido social-liberal y progresista», lo que significaba reforzar los polos «liberal-radical y liberal-social» ${ }^{122}$. Aceptando la condición de partido bisagra, el cambio estratégico suponía un acercamiento al PSOE, con ánimo de establecer una colaboración gradual, rompiéndose la incomunicación entre Suárez y González de los últimos tiempos. Ambos líderes se necesitaban y participaron de una común estrategia

118 Romero (2002): 214-215.

119 Laviña (2010): 138.

120 Calvo Sotelo (1990): 69-70, 81, 90.

121 Cambio 16, 27-11-1989: "Siete barones inician la revuelta en el CDS», destacando Eduardo Punset, Ińigo Cavero y Rafael Arias Salgado. Las críticas convergen en José Ramón Caso, pero Suárez no salía indemne.

122 Morodo, R., "Cambio en la continuidad», El Pais, 29-3-1990. Con motivo del cincuentenario de la muerte de Azaña, Morodo — sin citar al CDS — no dejó de señalar que «el azañismo puede, sin duda, constituir la base de un partido o de un movimiento», apuntando los aspectos principales del legado ideológico ("Revisión y actualización", $A B C$ Literario, 3-11-1990) e insistiendo en que Azaña se mantuvo siempre «en el marco de un liberalismo social y progresista» («La diabolización de Azańa», $E l$ Pais, 29-12-1990). 
azañista. Aunque en esa eventual escenificación de la nueva alianza social-azañista a Suárez solo le cabía representar el papel de Azaña, el CDS aparecía como un nuevo PAD, por paradójico que fuese.

Casi a modo de oración fúnebre, Carlos Revilla, diputado del CDS, anteriormente socialista, quiso resaltar las semejanzas entre el azañismo y el suarismo, prolongando el debate de algún acto del cincuentenario. Ambos líderes supieron poner en práctica su concepción de "una nueva España», enfrentándose al «dilema de las dos Espańas», una tarea que exigía "claridad de ideas, coraje político y valoración correcta de la circunstancia». "Azaña, y ese es su drama, no logrará el objetivo; Suárez lo alcanza y lo hace perdurable». La construcción de la libertad al servicio del individuo, la impronta social de su liberalismo, la defensa de una Espańa plural, «la grandeza de ánimo en los momentos graves y la sinceridad frente a sí mismos y frente a la sociedad», eran otros rasgos comunes que sobresalían en ese ejercicio comparativo. Suárez había fundado el CDS «para que la obra realizada dé sus verdaderos frutos, rescatando la operatividad progresista del centro político ante el peligro del bipartidismo", pero Revilla se abstenía de cualquier comentario sobre la situación presente del partido $^{123}$. Su homenaje, más que a Azaña, estaba dirigido a Suárez. De hecho, el mito de Azaña en la política española acabará dando paso al mito de Suárez.

\section{LA DISPUTA DE AZAÑA Y DEL CENTRO TRAS EL SACRIFICIO DE SUÁREZ}

Suárez dimitió como presidente del CDS tras el fracaso de su partido en las elecciones autonómicas y municipales de 1991. A la hora de apostar por un sucesor, el duque lo hizo públicamente por Morodo, lo que suponía igualmente una reafirmación del neoazañismo como identidad ideológica. La candidatura de Morodo fue derrotada en un congreso extraordinario. Un mes después, Suárez abandonaba su escaño en el parlamento. La segunda caída de Suárez, más que una agonía ${ }^{124}$ fue un nuevo sacrificio ritual ${ }^{25}$. En 1981, su dimisión — un sacrificio que se impuso a sí mismo ${ }^{126}$ — no sirvió para aplacar los demonios de la desunión dentro de UCD. «La tumba de Adolfo Suárez fue hecha desde fuera, pero lo enterramos desde dentro", dijo entonces un colaborador que le acompañaría en el $\mathrm{CDS}^{127}$. En 1991, la imagen sigue siendo

123 Revilla, C., «Azañismo y suarismo», El País, 19-12-1990.

124 Sarasqueta (1991).

125 La expresión, referida a Suárez, en Hernández (1996): 269.

126 Así lo recalca Meliá (1981): 11, 143.

127 Jesús Viana, citado por Hernández (1996): 283. 
válida, pero no hubo autosacrificio. El sacrificio de Suárez fue esta vez el desenlace necesario de un largo proceso ritual, facilitado por las conmemoraciones de Azańa, donde se libró la batalla cruenta del centro.

Al centramiento del PSOE durante el felipismo había seguido el de la derecha. El doble centro, que apeteciera siempre Suárez, acabó despedazando su propia figura y proyecto. El acoso de Aznar a Suárez, en un empeńo decidido de ocupar no solo el espacio, sino también la militancia potencial del $\mathrm{CDS}^{128}$, fructificó en aquellas elecciones de 1991, donde el PP, dando un vuelco al voto de las capitales, comenzó a labrar sus victorias posteriores. Sin terreno intermedio, el combate cuerpo a cuerpo entre PSOE y PP reintrodujo la memoria de la Guerra Civil en el discurso político, alejándolo del tono institucional manifestado con ocasión del cincuentenario del inicio del conflicto. El discurso guerracivilista, que tan eficaz se mostró en momentos decisivos como las elecciones generales de 1993 y 1996, vino a expresar la protesta del PSOE no solo ante la aproximación de la derecha a sus posiciones, sino por el uso político que hacía de Azaña en esa ofensiva.

Desde sus participaciones en el cincuentenario, Aznar reclama un reconocimiento colectivo del político republicano «sin incurrir para ello en la desfiguración o la mitomanía», y que sea «recordada íntegramente la historia de un verdadero símbolo político», evitándose "reivindicaciones patrimoniales guiadas por los intereses particulares de partido ${ }^{129}$. Sin embargo, su uso de Azańa no dejó de ser caprichoso, en su misma necesidad de reivindicar públicamente que el PP no provenía del franquismo vía Fraga, sino de la "gran tradición regeneracionista ${ }^{130}$. La misma tradición liberal que había invocado Suárez en los ochenta con el CDS, después de que Felipe González levantara las obras de Azaña durante la campaña triunfal de 1982 pretendiendo recoger toda la tradición progresista aunque no fuera socialista. Lo mismo hacía Aznar ahora apelando al conjunto de la tradición liberal, por vilipendiada que hubiera sido en el pasado por la derecha la herencia de Azaña. De un solo golpe, ambicionaba igualmente la herencia de Suárez, malquerido por Fraga en el pasado inmediato.

El oportunismo de Aznar se manifiesta en el uso intermitente de Azaña dentro de su estrategia de asalto al poder. Así, por ejemplo, la reivindicación de Azaña no aparece en el libro en que desarrolla su idea de España y el

128 El País, 20-4-1991. Nuevas incorporaciones al PP, como la de Luis Gamir, socialdemócrata de tintes liberales y teórico del centro en tiempos de UCD, reforzaron esa voluntad.

129 Aznar, J. M., ABC Literario, 3-11-1990.

130 Juliá, S., "Azaña, en la derecha», El País, 24-5-1994. 
concepto de segunda transición; Ortega ocupa ahí su lugar ${ }^{131}$. Tampoco se hace mención a él en la entrevista realizada por un medio cultural particularmente implicado en la promoción política de Aznar, donde no falta, sin embargo, un elogio de la tradición liberal-conservadora del siglo xix y, en particular, de la época de la Restauración ${ }^{132}$. Aznar parecía volver al Fraga de la Transición ${ }^{133}$. Desde el otro campo, asimismo, la acometida del PP en momentos de dificultad para el Gobierno socialista, hizo recordar las campañas contra Azańa durante la Segunda República ${ }^{134}$.

Publicitando un libro académico, Marichal no dudó en hacer heredero a Felipe González de la mejor tradición liberal y progresista española, incluido Ortega —únicamente recordado en su etapa filosocialista-, con una neta descalificación de Aznar, reciente vencedor en las elecciones de 1996 ${ }^{135}$. «Il faut s'engager pour connaître», escribió Marc Bloch y recuerda en su libro varias veces Marichal ${ }^{136}$. Si en 1980 había solicitado públicamente que no se instrumentalizase de manera partidaria la conmemoración de Azaña, las impredecibles consecuencias del uso político del pasado pesaron en el pronunciamiento final de quien más se había afanado hasta entonces en la rehabilitación intelectual de Azaña. La reafirmación azañista efectuada por Aznar durante la campaña de 1996 con la imagen del multitudinario mitin en Mestalla - emulando al que celebrara Azaña en 1935, ahí recordado, aunque algunos medios lo ocultaran- estaba excesivamente viva. No tardará en deshacerse por efectos de la crítica de la misma derecha intelectual ${ }^{137}$.

131 Aznar (1994): 55, 202-206.

132 Nueva Revista, 41, 1995: 14-48.

133 Si el «canofraguismo» fue un término acuñado entonces ( $A B C$, 6-6-1976), en 1997, con ocasión del centenario de la muerte de Cánovas del Castillo, llegado ya Aznar al poder, se producirá la alineación simbólica del PP con el histórico dirigente conservador, preferido sobre otros políticos monárquicos como Maura, que Tusell recomendó a los populares cuando estos reivindicaban a Azaña («Maura y no Azaña», $E l$ Mundo, 22-9-1994).

134 Estefanía, J., «Las campañas contra Azaña», El País, 27-9-1995, donde reproduce las notas de un escrito con igual título elaborado por el historiador Juan Pablo Fusi, que fue leído por Felipe González y repartido en el Consejo de Ministros.

135 Entrevista a Juan Marichal, El Pais, 2-4-1996.

136 Marichal (1995): 83-84, 320.

137 De la Cierva, recreando el mito de Azaña en la Segunda República, descalificó el uso realizado por Aznar, a quien — al igual que a Marichal— calificaba de «azañista fanático», recomendándole vivamente que leyese a Azańa, "pero a todo Azańa, no los fragmentos que le subraye alguno de sus ineptos consejeros» (De la Cierva, 1997: 12-13, 101, 118). La revista Razón Española —nacida en 1983 de la mano de G. 


\section{A MODO DE CONCLUSIÓN}

La doble conmemoración de Azaña, en 1980 y 1990, no respondió al viejo modelo de la conmemoración de Estado, sino que partió de la sociedad civil e implicó de manera progresiva a los distintos géneros de representación cultural, del ritual de la exposición al teatro y la televisión, y también narrativos, de la prensa a la literatura y la historiografía. La larga celebración permitió un sostenido ejercicio de reflexividad, con dos notas principales, pluralidad y serenidad, lo que favoreció la rehabilitación intelectual del gran símbolo republicano en la nueva España democrática. Con todo, la polémica saltó a la arena pública pasada la última conmemoración, siendo interpretado — también por la historiografía inmediata - como una tardía y abusiva utilización política de Azaña por parte de la misma derecha que antaño lo había demonizado.

El uso político de Azaña se localiza en toda la década, siendo obra fundamental de los políticos que intentaron rentabilizar desde el primer momento en beneficio propio la nueva memoria activada por las prácticas conmemorativas. Ello obliga a atender al refinamiento de estrategias políticas, a operaciones puntuales o al cambio de relaciones de fuerza. Tierno Galván fue el primero durante la Transición en revestirse de algunos de sus atributos, aunque no secundó al frente del PSP la pretensión de Morodo de convertir esas siglas en un verdadero partido neoazañista. El uso político de Azaña quedó, en todo caso, asociado a la afirmación y disputa del centroizquierda, adonde Suárez dirigió su mirada, con ánimo de reinventarse, a partir de las primeras elecciones democráticas. Su figura atrajo la comparación con Azaña en el fulgor de la primera conmemoración y creado el CDS buscó convertirlo en la enseña del neoazañismo, un nuevo PSP a su medida, retomando el viejo proyecto de Morodo, ahora colaborador suyo. Esta nueva transmutación política coincide con su alejamiento del rey, y pudo influir — aunque deba afirmarse todavía hipotéticamente- en ello.

Lo cierto, es que más allá de su operatividad, el neoazañismo trenzado ideológicamente por Morodo —un liberalismo social fronterizo con el socialismo liberal como manera de entender el centro progresista- define los

Fernández de la Mora- publicó en 1997-1998 algunos artículos que resucitaban la azañofobia (F. Paradela, «Azaña sectario», núm. 81; J. A. Cepeda, «Azaña, causante de la tragedia», núm. 83, y "Azańa tergiversado», núm. 92; A. Maestro, «Azaña, la charca del rencor», núm. 88), coincidiendo con la devolución de los llamados 'cuadernos robados' de Azaña (1997), sus Diarios de 1932-1933, editados por Juliá y que fueron presentados junto al presidente Aznar (el discurso de Aznar para la ocasión, en Nueva Revista, 55, 1998: 169-177). 
grandes ejes del discurso político de Suárez entre las dos conmemoraciones y fue incorporado a los propios textos congresuales del CDS. La retirada de Suárez no fue un fracaso personal ni un autosacrificio. Suárez fue sacrificado en el altar de la política en plena lucha cruenta por el centro y la memoria de Azaña, que no hizo sino acentuarse con su caída. El éxito del nuevo PP de Aznar se cifraba en su capacidad de recoger la herencia íntegra de Suárez — desde la apropiación del centro por él recreado a la de Azaña - y acabó por hacer olvidar la propia significación azañista de Suárez ${ }^{138}$.

En ese sentido, el auge de Azaña en los noventa, auténtica querella simbólica, es la expresión de un fin de ciclo que simboliza de alguna manera el mismo final de la Transición. Por encima de los usos partidistas de distinto signo, la resurrección de Azaña en la nueva España democrática no dejó de tener un efecto unificador. Tal es la función del mito si bien, como señala Nora, la memoria colectiva, en el marco de las sociedades avanzadas, es un lugar de encuentro y aprendizaje comunitario. Cabe seguir hablando hoy de «una» memoria nacional, pero cuya unidad está basada en «una reivindicación patrimonial dividida, en permanente desmultiplicación y búsqueda de cohesión ${ }^{139}$. La pervivencia del mito de Azaña y su capacidad de influir en la política española — más allá aún de las fechas aquí contempladas ${ }^{140}$ — así lo manifiesta.

\section{Bibliografía}

Aguado, E. (1972). Manuel Azaña Díaz. Barcelona: Nauta.

Aguilar, P. (1996). Memoria y olvido de la Guerra Civil española. Madrid: Alianza.

Alonso de los Ríos, C. (1997). La verdad sobre Tierno Galván. Madrid: Anaya.

Alted, A. (ed.) (1996). Manuel Azaña. Pensamiento y acción. Madrid: Alianza.

138 A ello contribuyó también el hecho de que — desde 1991, retirado de la vida política- sus discursos fueran elaborados por Eduardo Navarro, colaborador de los primeros tiempos con quien se reencontró de nuevo, el cual dio otro carácter a sus textos, acompañados siempre de una rica variedad de citas intelectuales, entre las que no se cuenta Azaña (Fuentes, 2011: 498-503). Jorge Trias subraya cómo Navarro «se dedicó a fabricar un discurso político e ideológico que diera sentido a todo lo que había hecho Suárez» (prólogo a Navarro, 2014: 25), pero ese mismo afán ha podido tener en algunos aspectos centrales el efecto contrario.

139 Nora (1993): 1010; y Nora (2011): 299-302, 414.

140 A partir de 2004, con Zapatero como presidente, se registra de manera particular un nuevo uso político de Azaña, cuyo estudio comparado con el aquí realizado revestiría sin duda interés, pero excede los límites de este trabajo. 
Amalric, J.-P. y Aubert, P. (eds.) (1993). Azaña et son temps. Madrid: Casa de Velázquez.

Arrarás, J. (1939). Memorias intimas de Azaña. Madrid: Ed. Españolas.

Azaña, M. (1966-1968). Obras Completas. Ed. de J. Marichal. México: Oasis.

— (1981). La velada en Benicarló. Contiene la versión teatral de J. L. Gómez y J. A. Gabriel y Galán. Madrid: Espasa-Calpe.

— (1982-1983). Antología. 1. Ensayos. 2. Discursos. Ed. de F. Jiménez Losantos. Madrid: Alianza.

(1997). Diarios, 1932-1933. Introducción de S. Juliá. Barcelona: Crítica.

— (2008). Obras Completas. 7 vols. Ed. de S. Juliá. Madrid: Centro de Estudios Políticos y Constitucionales, Taurus.

Aznar, J. M. (1994). España. La segunda transición. Madrid: Espasa Calpe.

Bodnar, J. (1992). Remaking America. Public Memory, Commemoration and Patriotism in the Twentieth Century. Princeton: PUP.

Bussière, E. y Moradiellos, E. (eds.) (2012). Memorias y lugares de la memoria en Europa. Bruselas: Peter Lang. Disponible en: https://doi.org/10.3726/978-3-0352-6214-8.

Calvo Sotelo, L. (1990). Memoria viva de la transición. Barcelona: Plaza y Janés.

Campo Vidal, M. (2012). Adolfo Suárez. El presidente inesperado de la Transición. Barcelona: RBA.

Cañizal, L., et al. (1991). La segunda república española a través de su presidente Manuel Azaña, en el cincuentenario de su muerte (1940-1990). Getafe: Ayuntamiento.

Carabias, J. (1980). Azaña, los que le llamábamos don Manuel. Barcelona: Plaza y Janés.

Carreras, J. J. y Forcadell, C. (eds.) (2003). Usos públicos de la Historia. Madrid: Marcial Pons.

Chamorro, E. (1981). Viaje al centro de UCD. Madrid: Planeta.

Cottret, B. y Henneton, L. (dirs.) (2010). Du bon usage des commémorations: histoire, mémoire et identité, XVIe-XXe siècles. Rennes: PUR.

De la Cierva, R. (1997). La Segunda República. El mito de Azaña. Madrid: Eudema.

Egido, M. A. (1998). Manuel Azaña; entre el mito y la leyenda. Valladolid: Junta de Castilla y Léon.

Espín, E. (1980). Azaña en el poder: el partido de Acción Republicana. Madrid: CIS.

Fernández Ordóńez, F. (1980). La España necesaria. Madrid: Taurus.

Fernández-Cormenzana, J. (1994). Cuaderno de La Prasle 1939-1940: memorias semiapócrifas de Manuel Azaña. Alcalá de Henares: Ayuntamiento.

Ferrer Solá, J. (1991). Manuel Azaña: una pasión intelectual. Barcelona: Anthropos.

Fuentes, J. F. (2011). Adolfo Suárez. Biografía politica. Barcelona: Planeta.

- (2016). Con el rey y contra el rey. Los socialistas y la monarquía. Madrid: La Esfera de los Libros.

García Santesmases, A. (1993). Repensar la izquierda: evolución ideológica del socialismo en la España actual. Barcelona: Anthropos.

Gillis, J. R. (1994). Commemorations. The Politics of National Identity. Princeton: PUP.

González Calleja, E. (2013). Memoria e historia. Vademécum de conceptos y debates fundamentales. Madrid: Los libros de la Catarata.

Gordón Ordás, F. (1962). Mi política en España. México: Victoria.

Hartog, F. y Revel, J. (2001). Les usages politiques du passé. París: EHESS.

Hernández, A. (1996). Adolfo Suárez. Fue posible la concordia. Madrid: Espasa. 
(2009). Suárez y el Rey. Madrid: Espasa.

Hermosilla, M. A. (1991). La prosa de Manuel Azaña. Córdoba: Universidad.

Jiménez Losantos, F. (1978). El desdén con el desdén: Manuel Azańa. Diwan, 1, 7-25.

- (1994). La última salida de Manuel Azaña. Barcelona: Planeta.

(1995). Lo que queda de España. Madrid: Temas de Hoy.

Juliá, S. (1990). Manuel Azaña, una biografía politica: del Ateneo al Palacio Nacional. Madrid: Alianza.

Laviña, C. (2010). Adolfo Suárez. Recuerdos prestados. Madrid: Laberinto.

Le Goff, J. (1991). El orden de la memoria. Barcelona: Paidós.

Mainer, J. C. (1991). La cultura. En M. Tuñón de Lara, et al. Transición y democracia (19731985) (pp. 313-457). Madrid: Labor.

Marco, J. M. (1988). La inteligencia republicana. Madrid: Biblioteca Nueva.

— (1990). Azaña. Barcelona: Mondadori.

- (1991). La creación de sí mismo: ensayo sobre la literatura autobiográfica de Manuel Azaña. Madrid: Biblioteca Nueva.

— y Serrano, V. A. (1990). Azaña: memoria gráfica, 1880-1940. Alcalá de Henares: Colegio del Rey.

Marichal, J. (1982). La vocación de Manuel Azaña. Madrid: Alianza.

— (1994). La restauración de Manuel Azaña. BILE, 21, 25-37.

— (1995). El secreto de España. Madrid: Taurus.

Meliá, J. (1981). Así cayó Adolfo Suárez. Barcelona: Planeta.

Morán, G. (1979). Adolfo Suárez. Historia de una ambición. Barcelona: Planeta.

— (1991). El precio de la transición. Barcelona: Planeta.

Morodo, R. (1982). Por una sociedad democrática y progresista. Madrid: Turner.

— (1987). Tierno Galván y otros precursores politicos. Madrid: El País.

- (2001). Atando cabos. Madrid: Taurus.

Navarro, E. (2014). La sombra de Suárez. Barcelona: Plaza y Janés.

Nora, P. (dir.) (1984-1993). Les lieux de mémoire. París: Gallimard.

- (1993). L'ère de la commémoration. En Les lieux de mémoire, III. Les France (pp. 975-1012). París: Gallimard.

- (2011). Présent, nation, mémoire. París: Gallimard.

Olábarri, I. (2013). Las vicisitudes de Clio. Salamanca: Universidad.

Osorio, A. (1980). Trayectoria política de un ministro de la Corona. Barcelona: Planeta.

Palau, A. (2007). L'héritage politique et intellectuel de Manuel Azaña: instrumentalisation ou réhabilitation. Hispanistica $X X, 25,55-65$.

Pasamar, G. (2014). Ha estallado la memoria. Las huellas de la Guerra Civil en la Transición. Madrid: Biblioteca Nueva.

Peña González, J. (1991). Manuel Azaña: el hombre, el intelectual y el político. Alcalá de Henares: Colegio del Rey.

Pulido Mendoza, M. (2011). A la búsqueda del «Genio de España»: Giménez Caballero, psicógrafo superrealista de Manuel Azaña. Bulletin of Hispanic Studies, 88 (1), 43-58. Disponible en: https://doi.org/10.3828/bhs.2010.46.

Quevedo, F. (2007). Pasión por la libertad. El pensamiento político de Adolfo Suárez. Barcelona: Altera. 
Reig, A. (1996). Tormento y éxtasis de Manuel Azaña: del infierno masónico al edén conservador. En A. Alted (ed.). Manuel Azaña. Pensamiento y acción (pp. 323-346). Madrid: Alianza.

Revel, J. y Levi, G. (eds.) (2002). Political uses of the past: the recent Mediterranean experience. Londres: Frank Cass.

Ricoeur, P. (2003) [2000]. La memoria, la historia y el olvido. Madrid: Trotta.

Rivas Cherif, C. (1980). Retrato de un desconocido: vida de Manuel Azaña (seguido por el epistolario de Manuel Azaña con Cipriano de Rivas Cherif de 1921 a 1937). Edición de Enrique de Rivas. Barcelona: Grijalbo.

Rojas, C. (1973). Azaña. Barcelona: Planeta.

Romero, A. (2002). Historia de Carmen. Barcelona: Planeta.

Saiz, J. R. (2012). Adolfo Suárez. La memoria del silencio. Santander: Cantabria Tradicional.

Sánchez-Prieto, J. M. (2005). El siniestro estrabismo. Historiografía y nación en la España contemporánea. Hispania, 219, 281-306. Disponible en: https://doi.org/10.3989/hispania.2005.v65.i219.164.

Sarasqueta, A. (1991). La agonía del duque: el enigma Adolfo Suárez. Madrid: Temas de Hoy. Serrano, V. A. y San Luciano, J. M. (eds.). (1991). Azaña. Madrid: Edascal.

Sevillano, J. (2003). La construcción de la memoria y el olvido en la España democrática. Ayer, 52, 297-319.

Tierno Galván, E. (1982). Cabos sueltos. Barcelona: Bruguera. 